\title{
Social support and depressive symptoms among physicians in tertiary hospitals in China: a cross-sectional study
}

\author{
Chang $\mathrm{Fu}^{1}$, Guowen Wang ${ }^{2}$, Xiuxin $\mathrm{Shi}^{3}$ and Fenglin $\mathrm{Cao}^{1 *}$
}

\begin{abstract}
Background: Social support is an important factor for individual's mental health. However, the association between social support and depressive symptoms among physicians in China' tertiary hospitals has not been explored. This study aimed to investigate its association among physicians stratifying by sex.

Methods: Six hundred fifty-six physicians were enrolled from 12 tertiary hospitals of Shandong Province, China. Depressive symptoms were assessed using the 10-item Center for Epidemiologic Studies Depression Scale. Social support was evaluated using the Social Support Rating Scale. Multiple linear regression analysis was used to examine the relationship between social support and depressive symptoms among physicians.

Results: The prevalence of depressive symptoms was $42.3 \%$ and the average social support score was $38.82 \pm 7.53$ among physicians. Lower subjective social support scores (male: $\beta=-0.317, p<0.001$; female: $\beta=-0.241, p<0.001$ ) and lower objective social support scores (male: $\beta=-0.218, p=0.038$; female: $\beta=-0.277, p=0.035$ ) were associated with high depressive symptoms among physicians. Lower support utilization scores $(\beta=-0.472, p<0.001)$ were associated with high depressive symptoms among male physicians.

Conclusions: Chinese physicians had a higher prevalence of depressive symptoms and lower social support than the Chinese general population. Objective and subjective social support were inversely associated with depressive symptoms among male and female physicians while support utilization was inversely associated with depressive symptoms among male rather than female physicians. It is critical to improve physicians' mental health through strengthening social support in China.
\end{abstract}

Keywords: Depressive symptoms, Physicians, Sex difference, Social support, Tertiary hospitals

\section{Introduction}

Depression has become one of the most common mental health problems worldwide, and it can significantly reduce the quality of life and workplace productivity [1]. Researchers have reported that, in the United States, 7.1\% of adults have experienced at least one major depressive episode [2], and in Europe, the prevalence of depression is $14.8 \%$ [3]. In China,

\footnotetext{
* Correspondence: fenglin@sdu.edu.cn

${ }^{1}$ Department of Health Psychology, School of Nursing and Rehabilitation, Cheeloo College of Medicine, Shandong University, No. 44 Wenhuaxilu Rd, Jinan 250012, Shandong, China

Full list of author information is available at the end of the article
}

the prevalence of lifetime depression among the general population is $6.9 \%$, and the 12-month prevalence of depression is $3.6 \%$ [4].

In recent years, the mental health of physicians has received increasing attention from researchers worldwide. Physicians are professionals who face high-level occupational stressors, such as long working hours, workload, and increasing professionalism-related demands in society [5]. As a result, they are vulnerable to experiencing depression [6]. Previous studies have demonstrated that the prevalence of depression among physicians is higher than the general

C C The Author(s). 2021 Open Access This article is licensed under a Creative Commons Attribution 4.0 International License, which permits use, sharing, adaptation, distribution and reproduction in any medium or format, as long as you give appropriate credit to the original author(s) and the source, provide a link to the Creative Commons licence, and indicate if changes were made. The images or other third party material in this article are included in the article's Creative Commons licence, unless indicated otherwise in a credit line to the material. If material is not included in the article's Creative Commons licence and your intended use is not permitted by statutory regulation or exceeds the permitted use, you will need to obtain permission directly from the copyright holder. To view a copy of this licence, visit http://creativecommons.org/licenses/by/4.0/ The Creative Commons Public Domain Dedication waiver (http://creativecommons.org/publicdomain/zero/1.0/) applies to the data made available in this article, unless otherwise stated in a credit line to the data. 
population $[7,8]$. As physicians are the direct providers of hospital services and a key element in the development of health services, depression among physicians is not only associated with their quality of life; but also hinders their professional performance and even influences the quality of healthcare [9]. Previous studies have identified several factors that influence depression among physicians, such as working hours [7] and age [8].

Social support refers to the social bonds, social integration, and primary group relations available to an individual [10]. It can be conveyed through verbal and nonverbal communication, and through actual or perceived exchanges of psychosocial or physical resources [11]. In recent years, the exploration of social support and its relationship with mental health has become one of the growing fields in psychology, particularly in the populations of older adults [12]. However, social support and mental health among physicians have received little attention. Previous studies revealed that social support is associated with depression among medical staff from developed countries $[5,13]$. However, the sex differences have not been considered in these studies. Researchers found that female physicians have lower social status than male physicians and do not receive an adequate level of respect from nurses and patients $[14,15]$. Thus, there may have sex differences among physicians in the relationship between social support and depressive symptoms.

Physicians in China may have heavier workloads than their counterparts in developed countries and have lower levels of social support than the Chinese general population. At the end of 2019, the number of physicians in China was 2.77 per 1000 population [16], which is lower than that in developed countries; for example, at the end of 2016, the number of physicians per 1000 population was 4.3 in Czech Republic, 4.0 in Italy, and 4.2 in Germany. In the process of healthcare reform, Chinese physicians have been asked to shoulder more responsibility for patient care, which may, in turn, have increased their workload [17]. In developed countries, physicians are usually afforded high social status and are well respected. However, in the past few years, the relationships between physicians and patients become intense and complex due to the occurrence of complications related to misdiagnosis and treatment [18]. Thus, increased stigmatization may lead to a lack of social support for physicians. However, there are few reports regarding both social support and depressive symptoms among Chinese physicians.

In China, tertiary hospitals are dedicated to providing medical care of patients with critical illness or complex diseases. Physicians in tertiary hospitals face more work stress than those in primary and secondary hospitals [19]. According to the Chinese Physician Practice
Situation White Paper [20], the average working time for physicians in tertiary hospitals was $51 \mathrm{~h}$ per week (exceeding China's legal limits of 40-h of work per week in China). We hypothesize that physicians in tertiary hospitals may have a high prevalence of depressive symptoms.

To maintain physicians' mental health, it is critical to investigate the prevalence of depressive symptoms, the level of social support, and their association among physicians in tertiary hospitals. Additionally, to better understand the association between social support and depressive symptoms among physicians, sex differences should be taken into consideration. Thus, we conducted a survey of social support and depressive symptoms among a sample of physicians in China's tertiary hospitals. This study will contribute to our understanding of both the level of social support and depressive symptoms among physicians and emphasizes the importance of actions required to improve the level of social support and to reduce depressive symptoms in this particular population.

\section{Methods \\ Aim}

The first aim of this study was to investigate the prevalence of depressive symptoms among physicians in tertiary hospitals in China. The second aim was to explore physicians' level of social support. The third aim was to determine the relationship between social support and depressive symptoms among physicians, taking sex differences into account.

\section{Study design, sample, and procedures}

This cross-sectional study was carried out from 30 July to 30 September 2020 in Shandong Province, China. Shandong is an eastern coastal province of China, with a geographic area of $157,900 \mathrm{~km}^{2}$. Shandong Province has sixteen prefecturelevel cities, its total population reached 100.7 million, and its Gross Domestic Product (GDP) exceeded one trillion US dollars by the end of 2019. It is claimed that Shandong Province is a typical province in terms of its population structure, social and culture aspects [21]. A multistage random sampling method was used. First, according to per capita GDP, 16 cities in Shandong Province were classified into three groups: high, medium, and low. Two cities were randomly selected from each group. Second, two tertiary hospitals were selected in each city. Third, two-thirds of the departments such as the internal medicine, surgery, obstetrics and gynecology, pediatrics, and emergency departments were selected from each sample hospital. A total of 1000 physicians in the sample departments were invited to take part in the survey. The inclusion criteria for the participants were that they were registered physicians, employed by the respective hospital, and voluntarily agreed to participate. Excluded participants included those who were on vacation or who were 
on temporary leave for research or career development, or who suffered from serious mental or physical disorders that may have hindered their participation. The questionnaire was developed using "Wenjuanwang" (https://www.wenjuan. $\mathrm{com} /$ ), which is a platform for the electronic questionnaires. We sent a web page related to the questionnaire survey to participants' mobile phones by using WeChat (a social media app). Of 1000 physicians in tertiary hospitals, 677 physicians participated in the survey. After excluding participants with missing data, we included 656 participants in our analysis. The effective response rate was $96.89 \%$.

\section{Measurements}

\section{Depressive symptoms}

Depressive symptoms were assessed using the 10-item Center for Epidemiologic Studies Depression Scale (CES-D 10). The CESD-10 was highly validated for use in Chinese general populations and demonstrated adequate validity and acceptable reliability in previous studies [22, 23]. Four options were used to answer the 10 items: $0=$ rarely, $1=$ some days $(1-2$ days $), 2=$ occa sionally (3-4 days), and $3=$ most of the time (5-7 days). The participants' answers were recorded as 0 (rarely) to 3 (most of the time) for the negatively scored questions and as 3 (rarely) to 0 (most of the time) for the positively scored questions. The total score ranges from 1 to 30, with higher scores indicating high depressive symptoms [23]. A cut-off point of 10 was recommended for this scale as indicating high depressive symptoms [24]. In the present survey, the Cronbach's alpha for CES-D 10 scale was 0.70 in male group and 0.70 in female group.

\section{Social support}

Social support was measured using the Chinese version of the Social Support Rating Scale (SSRS), which has been used in a wide range of studies on Chinese population due to its high reliability and validity [25]. This 10item scale consists of three dimensions: objective support (three items), subjective support (four items), and utilization of support (three items). The questions relating to objective support were Q2. What was your living situation in the past year?; Q6. What are your sources of financial support, and what helps you solve practical problems when you are in an emergency?; and Q7. What are your sources of comfort and concern when you are in an emergency? The questions regarding subjective support were Q1. How many friends do you have and how much support and help can they provide you?; Q3. How about your relationship with neighbors?; Q4. How about your relationship with colleagues?; and Q5. How much support and care have you received from family members? The questions focusing on utilization of support were Q8. How do you talk about trouble? Q9. How do you seek for help when you have trouble?; and Q10.
How often do you participate in activities organized by groups (such as party organizations, religious organizations, labor unions, etc.)?. For Q1-Q4 and Q8-Q10, the respondent selects only one option for each item, scoring 1-4 points for options A, B, C, and D, respectively. Q5 is divided into five subitems (spouse or lover, parents, child/children, siblings, and other family members). For each subitem, the response "none" scores 1 point; "rare," 2 points; "general," 3 points; and "full support," 4 points. For Q6 and Q7, the answer "no source" scores 0 points; otherwise, each source listed scores 1 point. The total SSRS score is the sum of the scores of the three subscales. A higher score indicates a higher level of social support [10]. In the present survey, the Cronbach's alpha for SSRS scale was 0.81 in male group and 0.80 in female group.

\section{Other variables}

The demographic characteristics of the survey included age, sex, marital status (married or single), educational level (college diploma, bachelor's degree, master's degree or higher), and monthly income. The professional characteristics comprised departments (surgical or nonsurgical), professional titles (primary, intermediate, senior), employment status (formal or contract employee), and working hours per week. Lifestyle factors included cigarette smoking (current/past, never) and alcohol consumption (current/past, never). Health status was assessed by self-rating on a five-point scale (very poor, poor, fair, good, and very good). Self-rated health was categorized as good (including very good and good), fair, or poor (including poor and very poor).

\section{Statistical analysis}

The data were analyzed using the Statistical Package for the Social Sciences (SPSS) version 20.0 (SPSS Inc., Chicago, IL, USA). Normal distribution of continuous variables was analyzed using the Kolmogorov-Smirnov test, Histogram plot, and P-P plot, which showed that they were normally distributed. Variance Inflation Factor (VIF) values larger than 10 were regarded as having presence of multicollinearity [26], and VIF of all independent variables in our study $<10$. Reliability was assessed with Cronbach's alpha. The characteristics of the overall respondents were described using means and standard deviations $(S D)$ for continuous data and percentages for categorical data. We divided our sample into two groups: male and female physicians. A comparison between groups was performed using independent $t$ tests for continuous variables and $\chi^{2}$-tests for categorical variables. Multiple linear regression analysis was used to examine the association between social support (objective social support, subjective social support, and support utilization) and depressive symptoms stratified by sex. 
Regression coefficient estimates $(\beta)$, standard error (SE) of $\beta, 95 \%$ confidence intervals $(\mathrm{CI})$ of $\beta$, and $p$-values were analyzed. The dependent variable was depressive symptoms. Potential confounders that were added into the multiple linear regression models were identified either through literature, univariate regression analysis, or Change-in Estimate procedures [27]. Statistical significance was set at $p$-value $<0.05$.

\section{Ethical considerations}

The Ethical Review Committee of the School of Nursing and Rehabilitation, Shandong University, approved the current study (approval number: 2020-R-50). All subjects gave their informed consent for inclusion before participating in the survey.

\section{Results}

\section{Sample characteristics}

Table 1 presents the characteristics of the participants. Of the 656 participants (mean age $=37.24$ years, $S D=9.47$ years), $54.5 \%$ were men, $80.5 \%$ were married, $55.5 \%$ had received a master's degree or higher, and $58.2 \%$ reported having a fair health status. Professionally, 53.0\% were working in surgical departments, $43.9 \%$ had a primary professional title, and $54.6 \%$ were formal employees. More than three-quarters of the participants were non-smokers (83.2\%), and $41.5 \%$ did not consume alcohol. Of the participants, $40.7 \%$ earned between $¥ 5000$ and $¥ 8000$ Renminbi (RMB) per month, and $94.4 \%$ worked more than $40 \mathrm{~h}$ per week. The mean score of CES-D 10 score was $8.97(S D=5.40)$. Additionally, using the 10 -item cutoff point, about $42.3 \%$ of the participants were found to have probable depression (male: $40.1 \%$; female: $44.8 \%$ ). There were statistically significant differences in age, marital status, monthly income, department, professional status, cigarette smoking, and alcohol consumption between male and female physicians $(p<0.05)$.

\section{The differences between social support scores among} participants and norms of the Chinese general population As Table 2 shows, the mean total social support score was $38.82(S D=7.86)$. Scores on all three dimensions of social support and the total social support score in our study were lower than the norms of the Chinese general population $[28,29]$. There were significant differences in the objective social support score, the support utilization score, and the total social support score between this study and the norms of the Chinese general population $(p<0.05)$.

\section{The differences between social support scores among male and female physicians}

As Table 3 shows, There were no statistically significant differences in scores of subjective support, objective social support, and the total social support score of male and female physicians. Support utilization score of female physicians was significant higher than male physicians $(P<0.05)$.

\section{Multiple linear regression analysis}

Table 4 shows the associations between social support and depressive symptoms. After adjusting for all covariates, the results of the multiple linear regression analysis showed that, among male physicians, a lower subjective support score was associated with high depressive symptoms $(\beta=-0.317, \mathrm{SE}=$ $0.058, p<0.001$ ), a lower objective support score was associated with high depressive symptoms $(\beta=-0.218, \mathrm{SE}=0.105$, $p=0.038$ ), and lower support utilization score was associated with high depressive symptoms $(\beta=-0.472, \mathrm{SE}=0.129, p<$ 0.001 ); Among female physicians, a lower subjective support score was associated with high depressive symptoms $(\beta=-$ $0.241, \mathrm{SE}=0.065, p<0.001$ ) and lower objective support score was associated with high depressive symptoms $(\beta=-0.277$, $\mathrm{SE}=0.131, p=0.035$ ). There was no significant correlation between support utilization score and depressive symptoms among female physicians.

\section{Discussion}

To our knowledge, this is the first study to investigate the prevalence of depressive symptoms and the association between depressive symptoms and levels of social support among Chinese physicians in tertiary hospitals. The present study will provide useful data for health policy-makers, hospital administrators, and society to take effective measures to further promote physicians' mental health.

In the present study, the prevalence of depressive symptoms among physicians was $42.2 \%$ (male: $40.1 \%$; female: $44.8 \%$ ), which was higher than the Chinese general population (12.6\%) [30]. Using the same measurement of depressive symptoms as in our study, the prevalence of depressive symptoms was $33.08 \%$ among older adults [31] and was 28.1\% among adolescents [32] in China. Despite the differences in participants' age, gender, and place of residence, when compared to the Chinese general population, our results showed that the prevalence of depressive symptoms among physicians in tertiary hospitals is significantly higher. Additionally, our results showed that the prevalence of depressive symptoms among Chinese physicians was higher than that reported in other studies from developed countries. Using the same measurement, the prevalence of depressive symptoms was $28 \%$ among physicians in Japan [3]. A systematic review and meta-analysis found that $28.8 \%$ of resident physicians have depression or depressive symptoms in the United States [33]. The relatively high prevalence of depressive symptoms among physicians in tertiary hospitals in China may be attributable to various 
Table 1 Characteristics of the participants according to a sex comparison

\begin{tabular}{|c|c|c|c|c|c|}
\hline Characteristics & Total Sample $(n=656)$ & Male $(n=357)$ & Female $(n=299)$ & $x^{2} / t$ & $p$-value \\
\hline Age, years, mean $\pm S D$ & $37.24 \pm 9.47$ & $38.80 \pm 9.76$ & $35.38 \pm 8.76$ & 4.731 & $<0.001$ \\
\hline Marital status, n(\%) & & & & 7.300 & 0.007 \\
\hline Married & $528(80.5)$ & $301(84.3)$ & $227(75.9)$ & & \\
\hline Single & $128(19.5)$ & $56(15.7)$ & $72(24.1)$ & & \\
\hline Educational level, n(\%) & & & & 0.417 & 0.812 \\
\hline College diploma & $18(2.7)$ & $10(2.8)$ & $8(2.7)$ & & \\
\hline Bachelor's degree & $274(41.8)$ & $153(42.9)$ & $121(40.5)$ & & \\
\hline Master's degree or higher & $364(55.5)$ & $194(54.3)$ & $170(56.9)$ & & \\
\hline Monthly income( $¥, \mathrm{RMB}), \mathrm{n}(\%)$ & & & & 14.715 & 0.002 \\
\hline$<5000$ & $140(21.3)$ & $65(18.2)$ & $75(25.1)$ & & \\
\hline $5000-8000$ & $267(40.7)$ & $136(38.1)$ & $131(43.8)$ & & \\
\hline $8000-10,000$ & $128(19.5)$ & $87(24.4)$ & $41(13.7)$ & & \\
\hline$>10,000$ & $121(18.4)$ & $69(19.3)$ & $52(17.4)$ & & \\
\hline Department, n(\%) & & & & 26.248 & $<0.001$ \\
\hline Surgical & $348(53.0)$ & $222(62.2)$ & $126(42.1)$ & & \\
\hline Non-surgical & $308(47.1)$ & $135(37.8)$ & $173(57.9)$ & & \\
\hline Professional status, n(\%) & & & & 17.817 & $<0.001$ \\
\hline Primary & $288(43.9)$ & $133(37.3)$ & $155(51.8)$ & & \\
\hline Intermediate & $191(29.1)$ & $107(30.0)$ & $84(28.1)$ & & \\
\hline Senior & $177(27.0)$ & $117(32.8)$ & $60(20.1)$ & & \\
\hline Employment status, n(\%) & & & & 1.656 & 0.198 \\
\hline Formal employee & $358(54.6)$ & $203(56.9)$ & $155(51.8)$ & & \\
\hline Contract employee & $298(45.4)$ & $154(41.3)$ & $144(48.2)$ & & \\
\hline Cigarette smoking, n(\%) & & & & 91.712 & $<0.001$ \\
\hline Current/past & $110(16.8)$ & $106(29.7)$ & $4(1.3)$ & & \\
\hline No & $546(83.2)$ & $251(70.3)$ & $295(98.7)$ & & \\
\hline Alcohol consumption, n(\%) & & & & 228.635 & $<0.001$ \\
\hline Current/past & $384(58.5)$ & $304(85.2)$ & $80(26.8)$ & & \\
\hline No & $272(41.5)$ & $53(14.8)$ & $219(73.2)$ & & \\
\hline Working hours per week, n(\%) & & & & 1.716 & 0.633 \\
\hline$\leq 40$ & $37(5.6)$ & $18(5.0)$ & $19(6.4)$ & & \\
\hline $41-50$ & $192(29.3)$ & $105(29.4)$ & $87(29.1)$ & & \\
\hline $51-60$ & $189(28.8)$ & $98(27.5)$ & $91(30.4)$ & & \\
\hline$>60$ & $238(36.3)$ & $136(38.1)$ & $102(34.1)$ & & \\
\hline Self-rated health, $n(\%)$ & & & & 1.028 & 0.598 \\
\hline Good & $204(31.1)$ & $117(32.8)$ & $87(29.1)$ & & \\
\hline Fair & $382(58.2)$ & $203(56.9)$ & $179(59.9)$ & & \\
\hline Poor & $70(10.7)$ & $37(10.4)$ & $33(11.0)$ & & \\
\hline Depression scale, mean \pm SD & $8.97 \pm 5.40$ & $8.84 \pm 5.36$ & $9.12 \pm 5.56$ & -0.661 & 0.509 \\
\hline Depressive symptoms, n(\%) & & & & 1.511 & 0.219 \\
\hline Yes & $277(42.2)$ & $143(40.1)$ & $134(44.8)$ & & \\
\hline No & $379(57.8)$ & $214(59.9)$ & $165(55.2)$ & & \\
\hline
\end{tabular}

1 USD $\approx ¥ 6.96$ RMB (August 2020 exchange rate). Abbreviations: RMB renminbi, $S D$ standard deviation 
Table 2 The difference of social support scores among participants and the norms of Chinese general population

\begin{tabular}{|c|c|c|c|c|}
\hline Variables & Total sample $(n=656)$ & Norms of general population & $t$ & $p$-value \\
\hline Subjective supports core, mean \pm SD & $23.59 \pm 5.21$ & $23.81 \pm 4.75$ & -1.079 & $>0.050$ \\
\hline Objective social support score, mean \pm SD & $7.87 \pm 2.54$ & $12.68 \pm 3.47$ & -48.428 & $<0.001$ \\
\hline Support utilization score, mean \pm SD & $7.36 \pm 1.91$ & $9.38 \pm 3.40$ & -27.046 & $<0.001$ \\
\hline Total social support score, mean \pm SD & $38.82 \pm 7.86$ & $44.38 \pm 8.38$ & -18.067 & $<0.001$ \\
\hline
\end{tabular}

Abbreviations: $S D$ standard deviation

factors. First, compared to physicians in developed countries, Chinese physicians have lower income, longer working hours, and heavier workloads. The socioeconomic status of Chinese physicians is lower and there is arguably a mismatch between workload and reward [34]. In our study, more than half of the physicians had a monthly income of less than $¥ 8000$ (RMB), approximately $\$ 1149$ (USD), and $65.2 \%$ of physicians worked more than $50 \mathrm{~h}$ per week, including $36.3 \%$ who worked more than $60 \mathrm{~h}$ despite the fact that the legal limit for working hours per week in China is $40 \mathrm{~h}$. According to the Medscape Physician Compensation Report 2020 [35], the average annual compensation for a physician in the United States was $\$ 341,000$ (USD), about $\$ 28,417$ (USD) per month, and the average number of working hours per week was $53.4 \mathrm{~h}$. The lower income and longer working hours could lead to increased depressive symptoms among Chinese physicians [36]. Second, compared to other professionals, medical staff are more likely to work in an intense workplace with weaker administrative measures, which may hinder their professional success or self-fulfillment [21]. In most hospitals, the professional promotion parameters usually emphasize the publications of scientific papers, funding, and awards. The professional skills and achievements are less likely to be considered [37]. However, most physicians often have heavy workloads and do not have sufficient time to engage in scientific research, which puts them at a disadvantage with regard to promotion. The difference among personal desires, goals, and reality may cause psychological stress among medical professionals [21] and may increase their depressive symptoms. Third, there was a significant difference in social status among Chinese physicians in comparison to those in developed countries; for example, there were some negative reports related to physicians' clinical practice in the past few years [15]. These may have a negative impact on psychological pressure and depressive symptoms among Chinese physicians [38]. Other influencing factors of high prevalence of depressive symptoms among physicians in China are worthy of further research.

Our results showed that physicians' total social support score was significantly lower than the Chinese general population. Regarding the three dimensions of social support, both objective social support and support utilization among physicians were significantly lower than the Chinese general population; only subjective social support was not. In the SSRS, objective social support refers to any kind of visible or actual social support, which is usually provided by family members, the government, local communities, and nongovernmental organizations. The lower social status of Chinese physicians may limit their access to objective social support from others, beyond family members. In addition, physicians often have long working hours and they have few time to participate in social activities. Support utilization represents the utilizing degree of the social support available. Previous studies have found that physicians are often reluctant to seek help because of their overconfidence [39]. Apart from this reason, we assume that physicians often work excessive hours and have few vacation days; thus, they have less time to join in social interactions, which may weaken their social support networks [40].

In our study, there is no difference in objective social support between male and female physicians. The explanation may be that both male and female physicians have longer working hours, fewer time to participate in social organizations, which may limit their access to objective social support from society. We found that there

Table 3 The differences of social support scores of male and female physicians

\begin{tabular}{lllll}
\hline Variables & Male $(\boldsymbol{n}=\mathbf{3 5 7})$ & Female $(\boldsymbol{n}=\mathbf{2 9 9})$ & $\boldsymbol{t}$ & $\boldsymbol{p}$-value \\
\hline Subjective support score, mean \pm SD & $23.87 \pm 5.18$ & $23.26 \pm 5.23$ & 1.497 & 0.135 \\
Objective social support score, mean \pm SD & $7.90 \pm 2.57$ & $7.84 \pm 2.50$ & $7.57 \pm 1.86$ & 0.269 \\
Support utilization score, mean \pm SD & $7.18 \pm 1.94$ & $38.67 \pm 7.81$ & -2.598 & 0.788 \\
Total social support score, mean \pm SD & $38.94 \pm 7.90$ & 0.452 & 0.652 \\
\hline
\end{tabular}

Abbreviations: $S D$ standard deviation 
Table 4 The association between social support and depressive symptoms stratified by sex

\begin{tabular}{|c|c|c|c|c|c|c|}
\hline \multirow[t]{2}{*}{ Variables } & \multicolumn{3}{|c|}{ Male physicians } & \multicolumn{3}{|c|}{ Female physicians } \\
\hline & $\mathrm{B}(\mathrm{SE})$ & $95 \% \mathrm{Cl}$ of $\beta$ & $p$-value & $\beta$ (SE) & $95 \% \mathrm{Cl}$ of $\beta$ & $p$-value \\
\hline Subjective supports score & $-0.317(0.058)$ & $-0.431 \sim-0.204$ & $<0.001$ & $-0.241(0.065)$ & $-0.370 \sim-0.113$ & $<0.001$ \\
\hline Objective supports score & $-0.218(0.105)$ & $-0.424 \sim-0.013$ & 0.038 & $-0.277(0.131)$ & $-0.532 \sim-0.014$ & 0.035 \\
\hline Support utilization score & $-0.472(0.129)$ & $-0.726 \sim-0.218$ & $<0.001$ & $-0.102(0.162)$ & $-0.425 \sim 0.214$ & 0.528 \\
\hline Age & $-0.026(0.049)$ & $-0.122 \sim 0.070$ & 0.596 & $-0.017(0.059)$ & $-0.135 \sim 0.098$ & 0.780 \\
\hline \multicolumn{7}{|l|}{ Marital status (ref. Married) } \\
\hline Single & $1.572(0.769)$ & $0.060 \sim 3.084$ & 0.042 & $1.729(0.810)$ & $0.134 \sim 3.328$ & 0.034 \\
\hline \multicolumn{7}{|c|}{ Education level (ref. college diploma) } \\
\hline Bachelor' degree & $1.247(1.427)$ & $-1.561 \sim 4.055$ & 0.383 & $-2.354(1.731)$ & $-5.578 \sim 1.066$ & 0.175 \\
\hline Master' degree or higher & $1.882(1.489)$ & $-1.047 \sim 4.812$ & 0.207 & $-3.779(1.786)$ & $-7.314 \sim-0.275$ & 0.035 \\
\hline \multicolumn{7}{|c|}{ Monthly income(¥, RMB) (ref. < 5000) } \\
\hline $5000-8000$ & $0.265(0.698)$ & $-1.108 \sim 1.639$ & 0.704 & $-0.233(0.727)$ & $-1.656 \sim 1.212$ & 0.749 \\
\hline $8000-10,000$ & $-0.984(0.825)$ & $-2.608 \sim 0.639$ & 0.234 & $0.026(1.020)$ & $-1.996 \sim 2.027$ & 0.980 \\
\hline$>10,000$ & $-2.406(0.933)$ & $-4.241 \sim-0.572$ & 0.010 & $-0.113(1.074)$ & $-2.239 \sim 1.995$ & 0.917 \\
\hline \multicolumn{7}{|c|}{ Cigarette Smoking (ref. Current/Past) } \\
\hline Never & $-0.476(0.503)$ & $-1.466 \sim 0.514$ & 0.345 & $-6.703(2.278)$ & $-11.162 \sim-2.181$ & 0.004 \\
\hline \multicolumn{7}{|c|}{ Alcohol consumption (ref. Current/Past) } \\
\hline Never & $0.357(0.651)$ & $-0.925 \sim 1.638$ & 0.584 & $-1.036(0.587)$ & $-2.231 \sim 0.092$ & 0.079 \\
\hline \multicolumn{7}{|l|}{ Department (ref. Surgical) } \\
\hline Non-surgical & $-0.382(0.470)$ & $-1.306 \sim 0.542$ & 0.417 & $0.500(0.532)$ & $-0.574 \sim 1.527$ & 0.348 \\
\hline \multicolumn{7}{|l|}{ Professional title (ref. Primary) } \\
\hline Intermediate & $1.855(0.720)$ & $0.439 \sim 3.270$ & 0.010 & $-1.385(0.773)$ & $-2.873 \sim 0.185$ & 0.074 \\
\hline Senior & $1.766(1.087)$ & $-0.372 \sim 3.905$ & 0.105 & $-1.311(1.320)$ & $-3.881 \sim 1.323$ & 0.322 \\
\hline \multicolumn{7}{|c|}{ Employment status (ref. Formal employee) } \\
\hline Contract employee & $0.024(0.566)$ & $-1.090 \sim 1.137$ & 0.967 & $-0.064(0.660)$ & $-1.384 \sim 1.218$ & 0.923 \\
\hline \multicolumn{7}{|c|}{ Weekly working hours (ref. $\leq 40$ ) } \\
\hline $41-50$ & $-1.140(1.092)$ & $-3.288 \sim 1.009$ & 0.297 & $2.014(1.152)$ & $-0.230 \sim 4.314$ & 0.082 \\
\hline $51-60$ & $0.079(1.120)$ & $-0.589 \sim 1.642$ & 0.944 & $2.830(1.164)$ & $0.531 \sim 5.117$ & 0.016 \\
\hline$>60$ & $-0.447(1.135)$ & $-2.679 \sim 1.785$ & 0.694 & $3.383(1.148)$ & $1.123 \sim 5.649$ & 0.003 \\
\hline \multicolumn{7}{|l|}{ Self-rated health (ref. good) } \\
\hline Fair & $2.681(0.517)$ & $1.664 \sim 3.697$ & $<0.001$ & $2.645(0.603)$ & $1.418 \sim 3.805$ & $<0.001$ \\
\hline Poor & $5.421(0.834)$ & $3.780 \sim 7.062$ & $<0.001$ & $6.316(0.985)$ & $4.327 \sim 8.218$ & $<0.001$ \\
\hline$\Delta \mathrm{F}$ & 13.255 & & & 9.093 & & \\
\hline$R^{2}$ & 0.454 & & & 0.408 & & \\
\hline Adjusted $R^{2}$ & 0.420 & & & 0.363 & & \\
\hline
\end{tabular}

Abbreviations: $\beta$ the coefficients, $C l$ confidence interval, SE standard error, RMB renminbi

is no difference in subjective social support between male and female physicians. From the present study, we found that there was no statistically significant differences in educational levels between the male and female physicians. In China, higher education degree means a principal definer of social status [41]. Thus, female physicians usually think they may have equal social status as male physicians and receive similar support from society. Our results showed that support utilization score among female physicians was significant higher than male physicians. This phenomenon may be explained by the issue of the traditional masculine norms. The social construction of masculinity including competitiveness, selfreliance, and less emotional express, may influence male's help-seeking behavior, while women are more likely than men to seek help from others for problems such as depression, physical discomfort, and stressful life events [42, 43]. 
Our findings revealed that subjective social support was inversely associated with depressive symptoms among Chinese physicians. Physicians tended to receive higher levels of subjective social support were less likely to have depressive symptoms. Subjective social support as a term for individuals' experience or feelings of social support, represents personal emotional experience and satisfaction with being supported, understood, and respected by others. Subjective social support helps individuals establish a positive self-image, self-efficacy, and higher self-esteem, which acts as protective factors against depressive symptoms [44, 45]. Moreover, a higher subjective support score means a better understanding of self-monitoring health status [46], which could have a positive impact on the reduction of depressive symptoms among physicians.

Objective social support refers to any type of visible or actual social support that may reduce work related stress [47]. It may help physicians buffer the effects of heavy workloads and maintain a better mental health status and well-being. In the present study, the findings showed that physicians with higher objective social support score were less likely to have depressive symptoms. Higher objective social support scores usually represents that they may receive more support from family members, the government, local communities, and nongovernmental organizations. Additionally, a friendly social environment is related to better mental health of individuals [48].

According to our data, male physicians with higher support utilization score were less likely to have depressive symptoms. Support utilization reflects the degree to which an individual proactively seeks help and social interaction. Higher support utilization indicated that individuals are more likely to seek help from family members, friends, social organizations, and society. From our data, male physicians with higher support utilization score were less likely to have depressive symptoms, which was consistent with the findings that a better connection with others can alleviate the harmful impact of stressful life events [10]. Another explanation is that individuals who participate in social interactions often have extensive social networks and more chances to access various forms of health-related information [49]. Encouraging physicians to widen their social networks may be useful to protect them from having depressive symptoms.

Interestingly, although female physicians had higher support utilization score than male physicians, there was no significant association between support utilization and depressive symptoms in our data. Female physicians' quality of social networks and family role may explain this phenomenon. The support from supervisors and colleagues are more important than that from family and friends in workplace [50]. Previous studies revealed that in comparison to male physicians, female physicians often have poor coworker relationships, get less respect, and do not obtain sufficient help from nurses and their male colleagues [51, 52]. Additionally, female physicians often shoulder the responsibility of taking care of their own families, including raising children and caring for the elderly and have less leisure time than their male colleagues [53], which can reduce their time and the quality of interaction with friends. Thus, the beneficial effects of support utilization on depressive symptoms may be limited among female physicians.

Our findings also showed that being single and having poor self-rated health status were associated with high depressive symptoms among physicians, which was consistent with the results from a previous study [7]. Nonsmokers had low depressive symptoms among female rather than male physicians, which was also consistent with the previous report that cigarette smoking has more harmful impact on woman's mental health [54]. From our findings, higher income was associated with low depressive symptoms only among male physicians while longer working time was associated with high depressive symptoms only among female physicians. A possible explanation for these phenomena is the gender differences in family's role. Women usually need to deal with dual pressures from work and family [14], while men have an advantage in the labor market [55]. Thus, men are assumed to play predominant role as financial providers. Those who earn less often have low self-esteem and high depressive symptoms [56]. While women including physicians usually spend more time on housewifery than their male counterparts [15]. Therefore, female physicians may be exhausted by long working time and housework load [57], resulting in high depressive symptoms. Several studies about the educational level with high depressive symptoms were conducted, but the results are still mixed [58, 59]. Our study revealed that higher educational level was associated with low depressive symptoms only among female physicians. It is suggested that higher educational level elevate their selfesteem and professional position, which can reduce the gender inequality and depressive symptoms [52, 56]. Our data showed a higher prevalence of depressive symptoms existed in male rather than female physicians with intermediate professional title, further study is needed to explain this phenomenon.

This study has several limitations. First, this was an online self-reporting questionnaire survey, so there was a risk of recall bias as well as selection and observation bias, which could result in inaccurate responses. Second, our study was a cross-sectional study, thus, the causal relationship between social support and depressive symptoms among physicians could not be determined. Though the present survey was conducted while 
progress has been made in containing COVID-19 and restrictions are gradually relaxed in China, the impact of the COVID-19 epidemic on physicians' mental health needs to be considered [60].

\section{Policy implications}

Based on our findings, we suggest that policy-makers and health administrators should (1) provide comprehensive counseling and support services for physicians to help them reduce depressive symptoms, regardless of gender; (2) improve the quality of social support and establish a harmonious coworker relationships for physicians, especially for female physicians; (3) reduce physicians' working hours and workloads, (4) increase physicians' income; (5) develop educational programs aimed to alleviate physicians' depressive symptoms. (6) take effective measures to prohibit stigma-related events toward medical staff; (7) optimize the current professional title promotion system.

\section{Conclusion}

Our study revealed that there was a higher prevalence of depressive symptoms and lower social support among male and female physicians in tertiary hospitals with comparison to the Chinese general population. Among both male and female physicians, higher scores for subjective social support and objective social support were associated with lower depressive symptoms. A higher support utilization score was associated with lower depressive symptoms only among male physicians. These findings signify that physicians' mental health in China should be considered as an important issue by hospital administrators and healthcare policy makers. To improve physicians' mental health through further strengthening social support and considering sex differences is critical.

\section{Abbreviations}

B: the coefficients; CES-D 10: 10-item Center for Epidemiologic Studies Depression Scale; Cl: Confidence interval; RMB: Renminbi; GDP: Gross domestic product; SD: Standard deviation; SE: Standard error

\section{Acknowledgments}

We thank all the administrators in each selected hospital who helped us to get the written informed consent and to distribute the questionnaires. We also thank all study participants who have been involved and contributed to the procedure of data collection.

\section{Authors' contributions}

CF and FC contributed to the study design. CF, GW, and XS contributed to the data collection. CF contributed to the data analysis. CF and FC wrote the main manuscript text. CF and FC revised the manuscript. All authors read and approved the final manuscript.

\section{Funding}

This study was funded by the Surface Project of National Natural Science Foundation of China (Grant Number:32071084). The funding source played no role in the design of this study; collection, analysis, and interpretation of data; writing of the report; or decision to submit the article for publication.

\section{Availability of data and materials}

The datasets generated and/or analyzed during the current study are not publicly available due to agreements with participants who restricted data sharing but are available from the corresponding author on reasonable request.

\section{Declarations}

\section{Ethics approval and consent to participate}

The research was approved by the Ethical Review Committee of the School of Nursing and Rehabilitation, Shandong University (approval number: 2020R-50). All subjects gave their informed consent for inclusion before participating in the survey. All methods in the present study were carried out in accordance with relevant guidelines and regulations.

\section{Consent for publication}

Not applicable.

\section{Competing interests}

The authors declare no conflict of interest.

\section{Author details}

${ }^{1}$ Department of Health Psychology, School of Nursing and Rehabilitation, Cheeloo College of Medicine, Shandong University, No. 44 Wenhuaxilu Rd, Jinan 250012, Shandong, China. ${ }^{2}$ Department of Education, Shandong Provincial Hospital Affiliated to Shandong First Medical University, No. 324 Jingwuweiqilu Rd., Jinan 250021, Shandong, China. ${ }^{3}$ Office of Medical Quality Control, Qilu Hospital, Cheeloo College of Medicine, Shandong University, No. 107 Wenhuaxilu Rd, Jinan 250012, Shandong, China.

Received: 4 March 2021 Accepted: 14 April 2021

Published online: 29 April 2021

\section{References}

1. Malhi GS, Mann JJ. Depression. Lancet. 2018;392(10161):2299-312. https:// doi.org/10.1016/S0140-6736(18)31948-2.

2. National Institute of Mental Health. Major Depression. https://www.nimh.nih. gov/health/statistics/major-depression.shtml. Accessed Feb 2019.

3. Alvarez-Galvez J, Rojas-Garcia A. Measuring the impact of multiple discrimination on depression in Europe. BMC Public Health. 2019;19(1):435. https://doi.org/10.1186/s12889-019-6714-4.

4. Huang Y, Wang Y, Wang H, Liu Z, Yu X, Yan J, et al. Prevalence of mental disorders in China: a cross-sectional epidemiological study. Lancet Psychiatry. 2019;6(3):211-24. https://doi.org/10.1016/S2215-0366(18)30511-X.

5. Tomioka K, Morita N, Saeki K, Okamoto N, Kurumatani N. Working hours, occupational stress and depression among physicians. Occup Med (Lond). 2011;61(3):163-70. https://doi.org/10.1093/occmed/kqr004.

6. Wallace JE. Mental health and stigma in the medical profession. Health (London). 2012;16(1):3-18. https://doi.org/10.1177/1363459310371080.

7. Gong Y, Han T, Chen W, Dib HH, Yang G, Zhuang R, et al. Prevalence of anxiety and depressive symptoms and related risk factors among physicians in China: a cross-sectional study. Plos One. 2014;9(7):e103242. https://doi. org/10.1371/journal.pone.0103242.

8. Hu WM, Yin XY, Yin XL, Zhu ZH, Guan LY, Hou WL, et al. Prevalence, socialdemographic and cognitive correlates of depression in Chinese psychiatric medical staff. J Affect Disord. 2020;263:60-3. https://doi.org/10.1016/j.jad.201 9.11.133.

9. Tsai YC, Liu CH. Factors and symptoms associated with work stress and healthpromoting lifestyles among hospital staff: a pilot study in Taiwan. BMC Health Serv Res. 2012;12(1):199. https://doi.org/10.1186/1472-6963-12-199.

10. Gu Y, Hu J, Hu Y, Wang J. Social supports and mental health: a crosssectional study on the correlation of self-consistency and congruence in China. BMC Health Serv Res. 2016;16(1):207. https://doi.org/10.1186/s12913016-1463-X.

11. McDougall MA, Walsh M, Wattier K, Knigge R, Miller L, Stevermer M, et al. The effect of social networking sites on the relationship between perceived social support and depression. Psychiatry Res. 2016;246:223-9. https://doi. org/10.1016/j.psychres.2016.09.018.

12. Liu D, Xi J, Hall BJ, Fu M, Zhang B, Guo J, et al. Attitudes toward aging, social support and depression among older adults: difference by urban and 
rural areas in China. J Affect Disord. 2020;274:85-92. https://doi.org/10.1016/ j.jad.2020.05.052

13. Bernburg M, Vitzthum K, Groneberg DA, Mache S. Physicians' occupational stress, depressive symptoms and work ability in relation to their working environment: a cross-sectional study of differences among medical residents with various specialties working in German hospitals. BMJ Open. 2016;6(6):e011369. https://doi.org/10.1136/bmjopen-2016-011369.

14. Wang L, Wang H, Shao S, Jia G, Xiang J. Job burnout on subjective wellbeing among Chinese female doctors: the moderating role of perceived social support. Front Psychol. 2020;11:435. https://doi.org/10.3389/fpsyg.202 0.00435 .

15. Song J, Cheng TC. How do gender differences in family responsibilities affect doctors' labour supply? Evidence from Australian panel data. Soc Sci Med. 2020;265:113475. https://doi.org/10.1016/j.socscimed.2020.113475.

16. National Health Commission of the People's Republic of China. Statistica bulletin of health development in 2019. http://www.nhc.gov.cn/guihuaxxs/ s10748/202006/ebfe31f24cc145b198dd730603ec4442.shtml. Accessed 6 June 2020.

17. Fu Y, Schwebel DC, Hu G. Physicians' workloads in China: 1998-2016. Int J Environ Res Public Health. 2018;15(8):1649. https://doi.org/10.3390/ijerph1 5081649.

18. Chinese doctors are under threat. Lancet. 2010; 376(9742): 657. doi: https:// doi.org/10.1016/S0140-6736(10)61315-3.

19. Liu J, Yu W, Ding T, Li M, Zhang L. Cross-sectional survey on job satisfaction and its associated factors among doctors in tertiary public hospitals in Shanghai, China. BMJ Open. 2019;9(3):e023823. https://doi.org/10.1136/ bmjopen-2018-023823.

20. Chinese Medical Doctor Association. Chinese Physician Practice Situation White Paper. Available online: http://www.cmda.net/rdxw2/11526.jhtml. Accessed 10 Jan 2018.

21. Zhao S, Zhang J, Liu Y, Ji H, Lew B. The association between psychological strains and life satisfaction: evidence from medical staff in China. J Affect Disord. 2020;260:105-10. https://doi.org/10.1016/j.jad.2019.09.006.

22. Boey KW. Cross-validation of a short form of the CES-D in Chinese elderly. Int J Geriatr Psychiatry. 1999;14(8):608-17. https://doi.org/10.1002/(sici)1 099-1166(199908)14:8<608:aid-gps991>3.0.co:2-z PMID: 10489651.

23. Luo Y, Zhu D, Nicholas S, He P. Depressive symptoms, health behaviors and risk of diabetes in Chinese mid-aged and older adults. J Affect Disord. 2019; 246:783-8. https://doi.org/10.1016/j.jad.2018.12.131.

24. Andresen EM, Malmgren JA, Carter WB, Patrick DL. Screening for depression in well older adults: evaluation of a short form of the CES-D (Center for Epidemiologic Studies Depression Scale). Am J Prev Med. 1994;10(2):77-84. https://doi.org/10.1016/S0749-3797(18)30622-6.

25. Xiao $\mathrm{S}$. The theoretical basis and research applications of the social support scale. J Clin Psychiatry. 1994;4:98-100.

26. Yang WC, Lin CH, Wang FC, Lu MJ. Factors related to the improvement in quality of life for depressed inpatients treated with fluoxetine. BMC Psychiatry. 2017;17(1):309. https://doi.org/10.1186/s12888-017-1471-3.

27. Weng HY, Hsueh YH, Messam LL, Hertz-Picciotto I. Methods of covariate selection: directed acyclic graphs and the change-in-estimate procedure. Am J Epidemiol. 2009;169(10):1182-90. https://doi.org/10.1093/aje/kwp035.

28. Deng L, Wang H, Chen J, Li L. Social support and negative emotion in parents of children with congenital heart disease before operation. Zhong Nan Da Xue Xue Bao Yi Xue Ban. 2013;38(9):915-9. https://doi.org/10.3969/j. issn.1672-7347.2013.09.008 [ in Chinese]

29. Zhang MY. Psychiatric rating scale manual. 2nd ed. Changsha: Hunan Science and Technology Press; 1993. p. 35-42. [ in Chinese]

30. Mental health in China: what will be achieved by 2020? Lancet. 2015; 385(9987):2548. https://doi.org/10.1016/S0140-6736(15)61146-1.

31. He S, Song D, Jian WY. The association between urbanization and depression among the middle-aged and elderly: a longitudinal study in China. Inquiry. 2020;57:46958020965470. https://doi.org/10.1177/004695802 0965470.

32. Cao R, Gao T, Hu Y, Qin Z, Ren H, Liang L, et al. Clustering of lifestyle factors and the relationship with depressive symptoms among adolescents in northeastern China. J Affect Disord. 2020;274:704-10. https://doi.org/10.101 6/j.jad.2020.05.064

33. Mata DA, Ramos MA, Bansal N, Khan R, Guille C, Di Angelantonio E, et al. Prevalence of depression and depressive symptoms among resident physicians: a systematic review and meta-analysis. JAMA. 2015;314(22):237383. https://doi.org/10.1001/jama.2015.15845.
34. Liu W, Zhao S, Shi L, Zhang Z, Liu X, Li L, et al. Workplace violence, job satisfaction, burnout, perceived organisational support and their effects on turnover intention among Chinese nurses in tertiary hospitals: a crosssectional study. BMJ Open. 2018;8(6):e019525. https://doi.org/10.1136/ bmjopen-2017-019525.

35. Medscape Physician Compensation Report 2020. https:/www.medscape.com/ slideshow/2020-compensation-overview-6012684\#1. Accessed 5 May 2020.

36. Rugulies R, Ando E, Ayuso-Mateos JL, Bonafede M, Cabello M, Di Tecco C, et al. WHO/LOO work-related burden of disease and injury: protocol for systematic reviews of exposure to long working hours and of the effect of exposure to long working hours on depression. Environ Int. 2019;125:51528. https://doi.org/10.1016/j.envint.2018.11.011.

37. Li Y. Chinese medical doctors negotiating the pressure of the publication requirement. Ibérica. 2014;28(28):107-26.

38. Wang LJ, Chen CK, Hsu SC, Lee SY, Wang CS, Yeh WY. Active job, healthy job? Occupational stress and depression among hospital physicians in Taiwan. Ind Health. 2011;49(2):173-84. https://doi.org/10.2486/indhealth.ms1209.

39. Davidson SK, Schattner PL. Doctors' health-seeking behaviour: a questionnaire survey. Med J Aust. 2003;179(6):302-5. https://doi.org/10.5694/ j.1326-5377.2003.tb05552.x

40. Nguyen AW, Walton QL, Thomas C, Mouzon DM, Taylor HO. Social support from friends and depression among African Americans: the moderating influence of education. J Affect Disord. 2019;253:1-7. https://doi.org/10.101 6/j.jad.2019.04.013

41. Goodman D. Class in contemporary China. Cambridge: Polity Press; 2014.

42. Addis ME, Mahalik JR. Men, masculinity, and the context of help seeking. Am Psychol. 2003;58(1):5-14. https://doi.org/10.1037/0003-066x.58.1.5.

43. Galdas PM, Cheater F, Marshall P. Men and health help-seeking behaviour: literature review. J Adv Nurs. 2005;49(6):616-23. https://doi.org/10.1111/j.13 65-2648.2004.03331.x.

44. Feng D, Su S, Wang L, Liu F. The protective role of self-esteem, perceived social support and job satisfaction against psychological distress among Chinese nurses. J Nurs Manag. 2018;26(4):366-72. https://doi.org/10.1111/ jonm.12523.

45. Gyasi RM, Phillips DR, Abass K. Social support networks and psychological wellbeing in community-dwelling older Ghanaian cohorts. Int Psychogeriatr. 2018;31(07):1-11. https://doi.org/10.1017/S1041610218001539.

46. Ma W, Kang D, Song Y, Wei C, Marley G, Ma W. Social support and HIV/STDs infections among a probability-based sample of rural married migrant women in Shandong Province, China. BMC Public Health. 2015;15(1):1170. https://doi.org/10.1186/s12889-015-2508-5.

47. Cao M, Kan J. Influence of social support on career identification in nurses. Nurs Res. 2010;24:380-1.

48. Rutter M. How the environment affects mental health. Br J Psychiatry. 2018; 186(1):4-6. https://doi.org/10.1192/bjp.186.1.4.

49. Fu C, Li Z, Mao Z. Association between social activities and cognitive function among the elderly in China: a cross-sectional study. Int J Environ Res Public Health. 2018;15(2):231. https://doi.org/10.3390/ijerph15020231.

50. Fukui S, Wu W, Salyers MP. Impact of supervisory support on turnover intention: the mediating role of burnout and job satisfaction in a longitudinal study. Admin Pol Ment Health. 2019;46(4):488-97. https://doi. org/10.1007/s10488-019-00927-0.

51. Tomizawa Y. Role modeling for female surgeons in Japan. Tohoku J Exp Med. 2019;248(3):151-8. https://doi.org/10.1620/tjem.248.151.

52. Gjerberg E, Kiølsrød L. The doctor-nurse relationship: how easy is it to be a female doctor co-operating with a female nurse? Soc Sci Med. 2001;52(2): 189-202. https://doi.org/10.1016/s0277-9536(00)00219-7.

53. Györffy Z, Dweik D, Girasek E. Workload, mental health and burnout indicators among female physicians. Hum Resour Health. 2016;14(1):12. https://doi.org/10.1186/s12960-016-0108-9.

54. Yue Y, Hong L, Guo L, Gao X, Deng J, Huang J, et al. Gender differences in the association between cigarette smoking, alcohol consumption and depressive symptoms: a cross-sectional study among Chinese adolescents. Sci Rep. 2015;5(1):17959. https://doi.org/10.1038/srep17959.

55. Wang C, Sweetman A. Gender, family status and physician labour supply. Soc Sci Med. 2013;94:17-25. https://doi.org/10.1016/.socscimed.2013.06.018.

56. Sowislo JF, Orth U. Does low self-esteem predict depression and anxiety? A meta-analysis of longitudinal studies. Psychol Bull. 2013;139(1):213-40. https://doi.org/10.1037/a0028931.

57. Li X, Zhang X. Female doctors in China: challenges and hopes. Lancet. 2015; 386(10002):1441-2. https://doi.org/10.1016/50140-6736(15)00403-1. 
58. Lorant V, Deliège D, Eaton W, Robert A, Philippot P, Ansseau M. Socioeconomic inequalities in depression: a meta-analysis. Am J Epidemiol. 2003;157(2):98-112. https://doi.org/10.1093/aje/kwf182.

59. Cross-national comparisons of the prevalences and correlates of mental disorders. WHO international consortium in psychiatric epidemiology. Bull World Health Organ. 2000;78(4):413-26.

60. Kathirvel N. Post COVID-19 pandemic mental health challenges. Asian J Psychiatr. 2020;53:102430. https://doi.org/10.1016/j.ajp,2020.202430.

\section{Publisher's Note}

Springer Nature remains neutral with regard to jurisdictional claims in published maps and institutional affiliations.

Ready to submit your research? Choose BMC and benefit from:

- fast, convenient online submission

- thorough peer review by experienced researchers in your field

- rapid publication on acceptance

- support for research data, including large and complex data types

- gold Open Access which fosters wider collaboration and increased citations

- maximum visibility for your research: over $100 \mathrm{M}$ website views per year

At $\mathrm{BMC}$, research is always in progress.

Learn more biomedcentral.com/submissions 